\title{
Motivation in Competitive Sport among Female Youth Athletes
}

\author{
Iris Orbach ${ }^{1,2 *}$, Hadar Gutin², Neta Hoffman², Boris Blumenstein ${ }^{2}$ \\ ${ }^{1}$ Ribstein Research Center, Wingate Institute, Netanya, Israel \\ ${ }^{2}$ College of Management Academic Studies, Rishon Lezion, Israel \\ Email: ^iorbach15@gmail.com
}

How to cite this paper: Orbach, I., Gutin, H., Hoffman, N., \& Blumenstein, B. (2021). Motivation in Competitive Sport among Female Youth Athletes. Psychology, 12, 943-958.

https://doi.org/10.4236/psych.2021.126057

Received: May 21, 2021

Accepted: June 27, 2021

Published: June 30, 2021

Copyright $\odot 2021$ by author(s) and Scientific Research Publishing Inc. This work is licensed under the Creative Commons Attribution International License (CC BY 4.0).

http://creativecommons.org/licenses/by/4.0/

\begin{abstract}
The focus of this study was understanding the reasons for starting and adhering to competitive activity among young female athletes. The current study involved 889 girls who practice regularly in a competitive setting. The subjects, ranged in age from 8 - 17 years participated in 10 different individual and team sport disciplines. The young athletes' reasons for participation in sports were measured by a questionnaire. Results of factor analysis for participation motives to start competitive sport revealed five different interpretable factors: IM (intrinsic motivation), EM (extrinsic motivation), TM (team motivation), WM (win motivation), and HM (health motivation). A two-way ANOVA with repeated measures (5 factors $\times 3$ age groups) revealed significant differences between the 5 factors within the young and middle groups. Post-hoc test with Bonferroni adjustments indicated that IM and WM were significantly different then EM and TM. When comparing between individual and team sport disciplines a two-way ANOVA ( 5 factors $\times 2$ team/individual) revealed that the intrinsic, winning and health motivations were stronger in team sport compared to individual sport. Results of the factor analysis for participation motives to continue competitive sport revealed three motivational factors similarly to the motives regarding starting activity (IM, EM, $\mathrm{TM}$ ) and another two different factors, CM (competitive motivation) and HM (hobby motivation). Post-hoc test with Bonferroni adjustment indicated on similar profile of the three age groups with dominant effect of IM and TM while some differences can be seen when comparing team and individual sports. The results should be shared with the coaching staff and club administration to improve the motivation of young female athletes to continue in competitive sport and to decrease the dropout rate from sport.
\end{abstract}

\section{Keywords}

Motivation, Youth Female Athlete, Competitive Sport 


\section{Introduction}

Motivation has been a central topic of study in sport and exercise psychology for several decades (Roberts, 2001; Spray et al., 2006; Weinberg et al., 2000). Because successful careers in competitive sport often start from a young age, it is important to understand what motivates sport activity initially, what maintains motivation for continued adherence, and finally what obstacles cause athletes to drop out of competitive sport. For example, in developed countries, between 50\% $70 \%$ of youth participate in at least one sport activity annually (Holt \& Knight, 2014). Data have shown that fewer female athletes relative to males participate in competitive sport (e.g., Bayyat, 2020). The gap between the genders increases with age. Up to age 12 the dropout rate from sport is greater for females than for males (Sabo, 2013). According to the World Health Organization (WHO), the rate of youth participating in organized sport is low: $17.5 \%$ for males and $4.1 \%$ for females ages 13 - 18 years old (Zach et al., 2012). Therefore, great interest has been shown in understanding the motivational reasons for participation in competitive sport among female youth athletes and the factors affecting those reasons.

Over the years, many researchers have tried to define and explain motivation through various theories and models in diverse contexts. The three theoretical models that have proven to be most useful are competence motivation theory (Harter, 1981), achievement goal orientation theory (Nicholls, 1984), and selfdetermination (intrinsic/extrinsic motives) theory (SDT: Deci \& Ryan, 1985). According to competence motivation theory, children are motivated to feel competent in achievement settings and engage in mastery attempts so that they can display competence (Harter, 1981, 1992). Achievement goal orientation theory posits that to understand the motivation of young athletes it is necessary to understand the function and meaning of their goal directed action (Nicholls, 1984).

Based on the literature, many studies have used Deci and Ryan's (1985) SDT as the appropriate framework for explaining motivational processes, especially in the world of sport and exercise. According to SDT, motivation can be divided into three types that move in a sequence: Internal Motivation, External Motivation and Amotivation.

Of these types of motivation, intrinsic motivation is considered to have the highest quality in terms of involvement in sport (Ryan \& Deci, 2000a, 2000b). According to the researchers, creating high internal motivation in individuals requires that three basic psychological needs be met: Autonomy (the level at which individuals perceive their behavior to be under their own control), Competence (individuals' perception of their ability to perform a certain action/ behavior) and Relatedness (a sense of belonging created by forming relationships with others) (Ryan \& Deci, 2000a).

According to research studies, significant components of individual intrinsic motivation include enjoyment of play and competition (Soares et al., 2013), im- 
proving abilities and performance, the ability to face challenges and competitions (Vignadelli et al., 2018), a sense of ability, a sense of comfort with oneself, and belonging and connection to a team (Zarrett et al., 2020). It was explained that these interpersonal factors are Influenced both by personal experiences in sports and by the opinions of other important people in their environment such as family and friends (Zarrett et al., 2020). An example of these findings can be seen in a study of swimmers (Fredricks \& Eccles, 2006) which found that fun and enjoyment, maintaining fitness, improving abilities, team atmosphere, and challenge were primary and more significant reasons for participating in sports than the pressure of parents and friends, and the desire to be popular (Ciocan \& Milon, 2017).

Various studies have shown that girls and boys have different motivation and needs in the context of engaging in sports (Azzarito \& Solmon, 2009; Bayyat, 2020; Crosnoe, 2001; Daley \& O’Gara, 1998; Meece et al., 2006). For example, one study found that girls participate in sport more for internal rather than external motives (e.g., fun, being with friends) compared to boys (Chantel et al., 1996; Wang \& Liu, 2007). In another study, gender motivations were compared in team sports versus individual sports, and it was found that female athletes had higher overall motivation to participate in sports than male athletes (Moradi et al., 2020). Another finding in the context of gender comparisons in team sports (i.e., football and volleyball) showed that girls and boys attached importance to the same three motives for participating ("technical ability", "competition" and "group activity") but differed in the level of importance of each factor (Vignadelli et al., 2018). This, added to findings showing a significant gap in drop-out numbers between the genders, increases the importance of investigating motivational patterns among female athletes to join sport activity, to persist in participation and finally to drop out.

According to the stages of change model, individuals at different stages of exercise participation are motivated by different factors (Prochaska et al., 1992). This means that the motivational approach used with girls just starting to participate in sport should be different than the motivational approach used with girls already involved and participating in sport. It has been shown that individuals' reasons for starting an exercise program differ from those for continuing a program over time. Specifically, initial motives for participation tend to be more extrinsic in nature, whereas motives relating to adherence tend be more intrinsic in nature (Ryan \& Deci, 2000a).

Based on the above, it was hypothesized that differences exist in motivational patterns across the timeline of girls' sport participation (i.e., beginning, continuation, dropout). This knowledge is important for designing effective intervention approaches to increase the percentage of girls participating in sport and their progress in the training process. This paper presents data pertaining to the beginning and continuation of competitive sport; dropout data are presented in a separate paper. 


\section{Methods}

\subsection{Participants}

The current study involved 889 girls who practice regularly in a competitive setting as part of a national project for advancing women's sport. Participants ranged in age from 8 - 17 years, were drawn from different geographical areas within the country and participated in 10 sports, both individual and team (see Table 1). The individual sports were swimming $(\mathrm{n}=98)$, track and field $(\mathrm{n}=$ $95)$, judo $(\mathrm{n}=97)$, gymnastics $(\mathrm{n}=116)$, sailing $(\mathrm{n}=49)$, and windsurfing $(\mathrm{n}=$ 12). The team sports were football $(\mathrm{n}=113)$, handball $(\mathrm{n}=109)$, basketball $(\mathrm{n}=$ $91)$ and volleyball $(n=109)$. All sports were divided into three age groups to track the athletes' development according to chronological age. The age groups were: 8 - 10 years old (young): $11-13$ years old (middle) and $14-17$ years old (adult). In handball, because children join at a later age than in other sports, participants were divided into two age groups (8 - 13: middle, 14 - 17: adult).

\subsection{Instrument}

The modified Gould, Feltz, and Weiss (1985) questionnaire for examining young athletes' reasons for participating in sports was tailored to the research objectives. The questionnaire is divided into three parts. In the first part, which includes 35 items, the athletes were asked to rate the reasons for choosing to start participating in the sport. In the second part, with 44 items, the athletes were asked to choose the reasons to continue participating in the sport. Finally, in the third part, with 20 items, the athletes were asked to rate obstacles that interfere with and/or make it difficult for them to participate in sports. A 5-point Likert Scale from 1 ("not important at all") to 5 ("very important") was used for each item in the questionnaire. The instructions noted that there are many different reasons to participate in competitive sport and the researchers were interested in

Table 1. Number of participants by sport.

\begin{tabular}{ccc}
\hline Sport & Number of participants & Percentage of total participants \\
\hline Swimming & 98 & $11 \%$ \\
Track and Field & 95 & $11 \%$ \\
Judo & 97 & $11 \%$ \\
Windsurfing & 12 & $1 \%$ \\
Rhythmic Gymnastics & 116 & $13 \%$ \\
Football & 113 & $13 \%$ \\
Handball & 109 & $12 \%$ \\
Basketball & 91 & $10 \%$ \\
Volleyball & 109 & $12 \%$ \\
Sailing & 49 & $6 \%$ \\
Total & $\mathbf{8 8 9}$ & $\mathbf{1 0 0 \%}$ \\
\hline
\end{tabular}


the participants' own unique reasons for participation. In addition, the athletes were asked to answer a demographic questionnaire about their background and general experience in sports (e.g., years of training, participation in competitions, level of achievement, etc.).

\subsection{Procedures}

A pilot study was conducted to examine the research procedure in one team sports, basketball, and in one individual sports, rhythmic gymnastics. The results of the pilot study were presented at a national conference for women's sport in 2016. Afterwards, the 889 participants were recruited for the current study. A coordinator from the national program was selected for each sport discipline and was responsible for data collection from that sport. The coordinators were summoned to a seminar where they received a lecture and instruction on how to disseminate and conduct the questionnaire. Athletes completed the questionnaire anonymously in 25 - 30 minutes. Initial data from the study were presented at an international conference on Women's Sport Participation and Gender Equality in March 2019, in Madrid.

\section{Results}

Factor analysis (varimax rotation, ML extraction) for participation motives to start and continue competitive sport was conducted to determine whether common themes appeared across the questionnaire.

\subsection{Motivational Factors for Starting to Participate in Competitive Sport}

Results of the factor analysis for the motivational factors to start competitive sport revealed five different interpretable factors. The five factors extracted with eigenvalue greater than 1 (see Table 2) explained 59.4\% of the variance. Factor 1 was labeled Intrinsic Motivation (IM) and was related to reasons within the individual (e.g., "I want"). Factor 2 was termed Extrinsic Motivation (EM) and was related to motives outside the athlete (e.g., "I want to be more popular"). The third factor was labeled Team Motivation (TM) and included motives that connect the athlete to the team (e.g., "I like to be part of the team"). The fourth factor was labeled Win Motivation (WM) and was related to the excitement of competition and the rewards it supplied (e.g., "I like to win"). The fifth factor was termed Health Motivation (HM) and was related to improving general health (e.g., "I want to be healthy").

A two-way ANOVA with repeated measures (5 factors $\times 3$ age groups) was conducted to investigate differences in relation to the five factors to start participation in competitive sports across age groups. Results indicated a significant main effect for factors: $\mathrm{F}(4,3500)=168.32, p<0.001$, significant main effect for age groups: $\mathrm{F}(2,875)=16.66, p<0.001$ and a significant interaction between the factors and age groups: $\mathrm{F}(8,3500)=4.163, p<0.001$ (see Figure 1). 
Table 2. Motivational factors to start competitive sport.

\begin{tabular}{cc}
\hline Factor & $\alpha$ Cronbach \\
\hline $\mathrm{IM}=$ Intrinsic Motivation & 0.937 \\
$\mathrm{EM}=$ Extrinsic Motivation & 0.917 \\
$\mathrm{TM}=$ Team Motivation & 0.871 \\
$\mathrm{WM}=$ Win Motivation & 0.836 \\
$\mathrm{HM}=$ Health Motivation & 0.896 \\
\hline
\end{tabular}

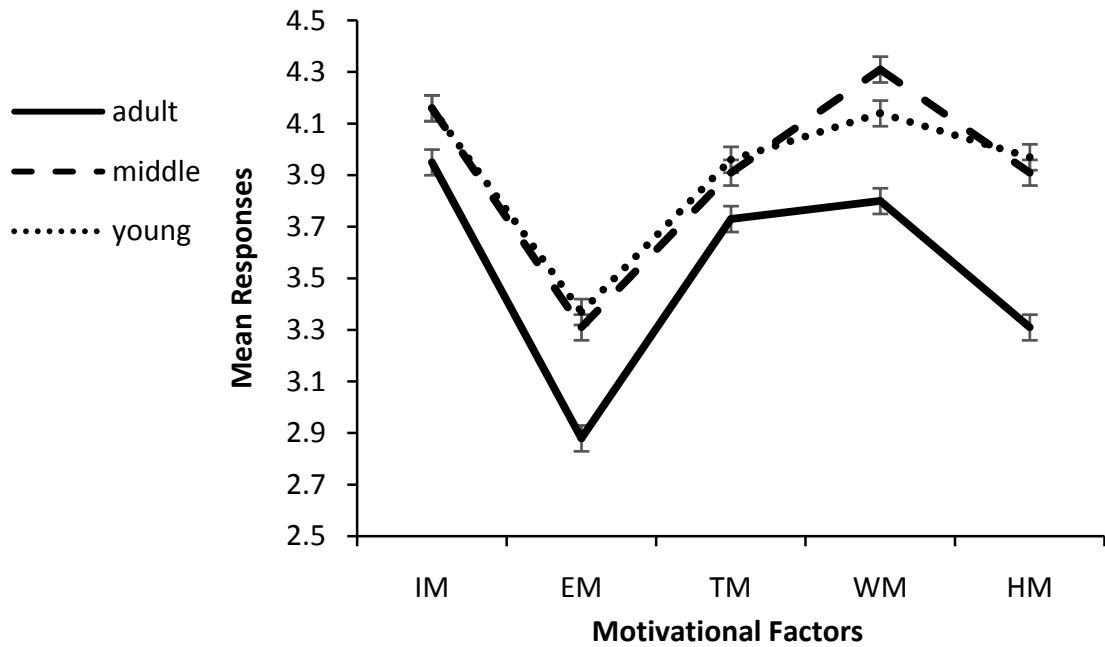

Figure 1. Five motivational factors to start competitive sport across three age groups.

Post-hoc test with Bonferroni adjustment indicated that there were no differences between the young and middle age groups, and both groups were different than the adult group. Significant differences were found between the five factors within the young and middle groups. IM and WM were significantly different than EM and TM. In addition, IM was significantly different than HM (see Table 3).

The results for the motivation to start competitive sport were discussed only regarding the young group. There were two reasons for this decision. First, the young and middle group presented the same statistical profile. Second, when investigating the reasons for starting competitive activity the responses of the adult group may not be reliable due to the length of time (approximately 2 - 6 years) that passed between this research and the time in which the young athletes started sport activity.

To compare individual and team sport disciplines, a two-way ANOVA (5 factors $\times 2$ team/individual) was conducted for the young group in relation to major motives to start participation in competitive sports. Results indicated significant main effect for factors: $\mathrm{F}(4,908)=37.91, p<0.001$; significant main effect for individual/team sports: $\mathrm{F}(1,227)=9.25, p<0.039$; and finally a significant interaction: $\mathrm{F}(4,908)=6.52, p<0.001$. Post-hoc test with Bonferroni adjustment found differences in EM, WM and HM (i.e., in team sports the results for the 
Table 3. Means and SD for the five motivational factors for starting competitive sport across age groups.

\begin{tabular}{cccc}
\hline & Young & Middle & Adult \\
\hline IM = Intrinsic Motivation & $4.16 \pm 0.66$ & $4.16 \pm 0.67$ & $3.95 \pm 0.80$ \\
EM = Extrinsic Motivation & $3.37 \pm 1.02$ & $3.31 \pm 0.96$ & $2.88 \pm 0.87$ \\
TM = Team Motivation & $3.96 \pm 1.06$ & $3.91 \pm 1.01$ & $3.73 \pm 1.13$ \\
WM = Win Motivation & $4.14 \pm 1.17$ & $4.13 \pm 1.18$ & $3.80 \pm 1.23$ \\
HM = Health Motivation & $3.97 \pm 1.24$ & $3.91 \pm 1.21$ & $3.31 \pm 1.47$ \\
\hline
\end{tabular}

three factors were higher compared to individual sports). When looking at the profile of team sports in the young group IM, TM, and HM were significantly different than EM. In individual sports IM, WM, and TM were significantly different than EM and HM. In addition, IM was significantly different than WM. See Figure 2 and Table 4 for differences between team and individual sports among the young group. The same profile was found for the middle group.

\subsection{Motivational Factors for Continuing Participation in Competitive Sport}

Results of the factor analysis for motives to continue participation in competitive sport revealed five different interpretable factors. The five factors were extracted with eigenvalue greater than 1 (see Table 5) and explained $59.4 \%$ of the variance. Factor 1 was labeled Intrinsic Motivation (IM) and was related to reasons within the individual (e.g., "I want"). Factor 2 was termed Extrinsic Motivation (EM) and was related to motives outside the athlete (e.g., "I wanted to raise my status"). The third factor was labeled Team Motivation (TM) and included motives that connect the athlete to the team (e.g., "I like to be part of the team"). The fourth factor was labeled Competitive Motivation (CM) and was related to competition (e.g., "I like the pressure of competition"). The fifth factor was termed Hobby Motivation (HobM) and was related to general motives (e.g., "I like to get out of the house").

A two-way ANOVA with repeated measures (5 factors $\times 3$ age groups) was conducted to investigate the differences in relation to the five motivational factors to continue participation in competitive sports across age groups. Results indicated a significant main effect for factors: $\mathrm{F}(4,3424)=209.84, p<0.001$, and a significant interaction between the factors and age groups: $\mathrm{F}(8,3424)=7.29, p$ $<0.001$ (see Figure 3).

Post-hoc test with Bonferroni adjustment indicated differences between the five factors except for similarities between CM and HobM. In addition, EM of the adult group was significantly lower than EM for the two other groups (i.e., young and middle) (see Table 6).

To compare individual and team sport disciplines, a two-way ANOVA (5 factors $\times 2$ team/individual) was conducted for the three age groups in relation to major motives to continue participation in competitive sports. 
Table 4. Means and SD for the five motivational factors to start competitive sport for team/individual sports (young group).

\begin{tabular}{ccc}
\hline & Team & Individual \\
\hline $\mathrm{IM}=$ Intrinsic Motivation & $4.21 \pm 0.62$ & $4.10 \pm 0.73$ \\
$\mathrm{EM}=$ Extrinsic Motivation & $3.51 \pm 0.96$ & $3.01 \pm 1.07$ \\
$\mathrm{TM}=$ Team Motivation & $4.00 \pm 1.07$ & $4.00 \pm 1.00$ \\
$\mathrm{WM}=$ Win Motivation & $3.31 \pm 1.04$ & $3.79 \pm 1.36$ \\
$\mathrm{HM}=$ Health Motivation & $4.18 \pm 1.08$ & $3.50 \pm 1.55$ \\
\hline
\end{tabular}

Table 5. Motivational factors for continue competitive sport.

\begin{tabular}{cc}
\hline Factor & $\alpha$ Cronbach \\
\hline $\mathrm{IM}=$ Intrinsic Motivation & 0.962 \\
$\mathrm{EM}=$ Extrinsic Motivation & 0.924 \\
$\mathrm{TM}=$ Team Motivation & 0.870 \\
$\mathrm{CM}=$ Competitive Motivation & 0.828 \\
$\mathrm{HobM}=$ Hobby Motivation & 0.855 \\
\hline
\end{tabular}

Table 6. Means and SD for the five motivational factors to continue competitive sport across the three age groups.

\begin{tabular}{cccc}
\hline & Young & Middle & Adult \\
\hline IM & $4.29 \pm 0.66$ & $4.33 \pm 0.61$ & $4.28 \pm 0.61$ \\
EM & $3.69 \pm 1.06$ & $3.47 \pm 1.06$ & $3.15 \pm 0.93$ \\
TM & $3.92 \pm 1.06$ & $3.94 \pm 0.92$ & $3.85 \pm 0.95$ \\
CM & $3.78 \pm 1.01$ & $3.75 \pm 1.02$ & $3.74 \pm 1.01$ \\
HobM & $3.81 \pm 1.10$ & $3.76 \pm 0.99$ & $3.66 \pm 1.04$ \\
\hline
\end{tabular}

age_r: young

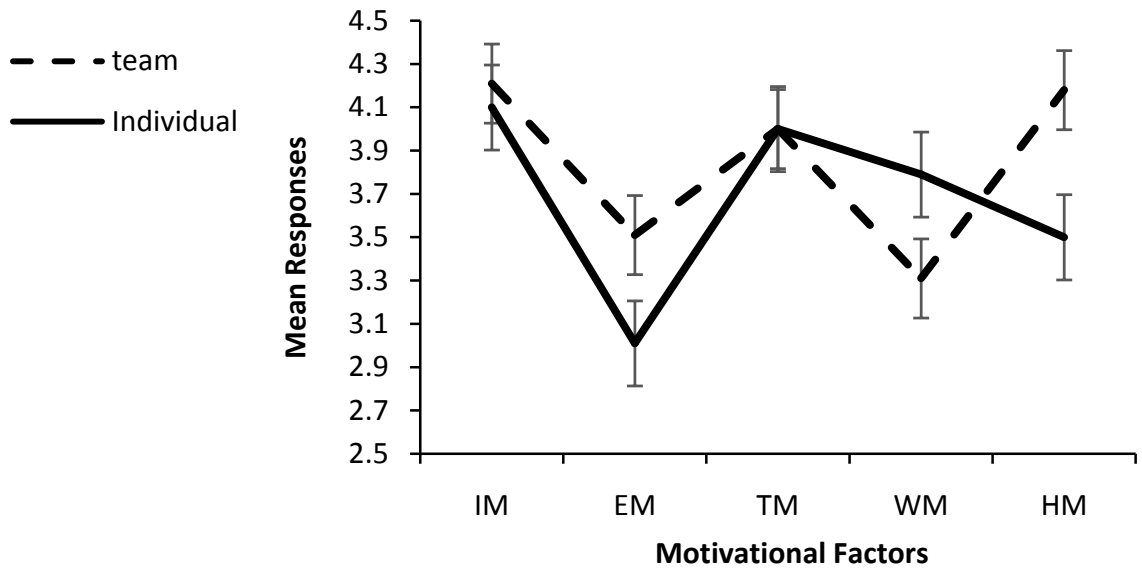

Figure 2. Profile for team and individual sport regarding motivational factors to start competitive sport for the young group. 


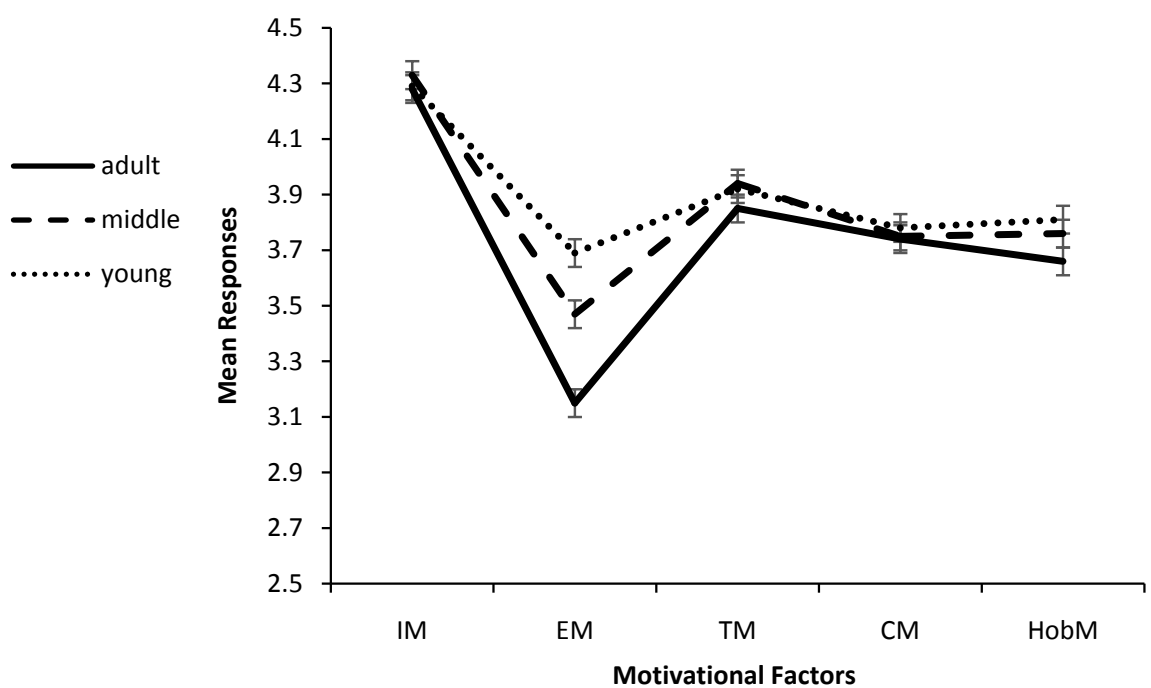

Figure 3. Five motivational factors to continue competitive sport across the three age groups.

Young Group: Results indicated a significant main effect for factors: $\mathrm{F}(4,888)$ $=40.10, p<0.001$; a significant main effect for individual/team sports: $\mathrm{F}(1,222)$ $=5.04, p<0.026$; and finally a significant interaction: $\mathrm{F}(4,888)=6.43, p<0.001$. Post-hoc test with Bonferroni adjustment found differences in EM of individual sports vs team sports. In addition all factors were different from each other except for CM and HobM (see Table 7 and Figure 4).

Middle Group: Results indicated a significant main effect for factors: F(4, $1440)=98.84, p<0.001$; a significant main effect for individual/team sports: $\mathrm{F}(1,360)=9464.25, p<0.001$; and finally a significant interaction: $\mathrm{F}(4,1440)=$ 3.60, $p<0.006$. Post-hoc test with Bonferroni adjustment found that all factors were different from each other except for CM and HobM (see Table 7 and Figure 5).

Adult Group: Results indicated a significant main effect for Factors: $\mathrm{F}(4,664)$ $=53.47, p<0.001$, and a significant interaction: $\mathrm{F}(4,664)=3.31, p<0.011$. Post-hoc test with Bonferroni adjustment found that all factors were different than each other except for TM and HobM (see Table 7 and Figure 6).

\section{Discussion}

The motivation for participation among youth female athletes has been an important topic of study in recent decades (Bayyat, 2020). The focus of this study was on understanding the reasons that young female athletes start and adhere to competitive activity. The ultimate goal is to gain insight into how to decrease dropout rate in individual and team sport disciplines. The results indicate that among young participants (i.e., 9 - 11 years old) intrinsic motives were the most dominant reasons to start competitive activity. The desire to win was also dominant in influencing the decision to start participating in sport. On the other hand, external and team motivation were significantly less dominant among 
Table 7. Means and SD for motivational factors to continue competitive sport in team/individual sports (three age groups).

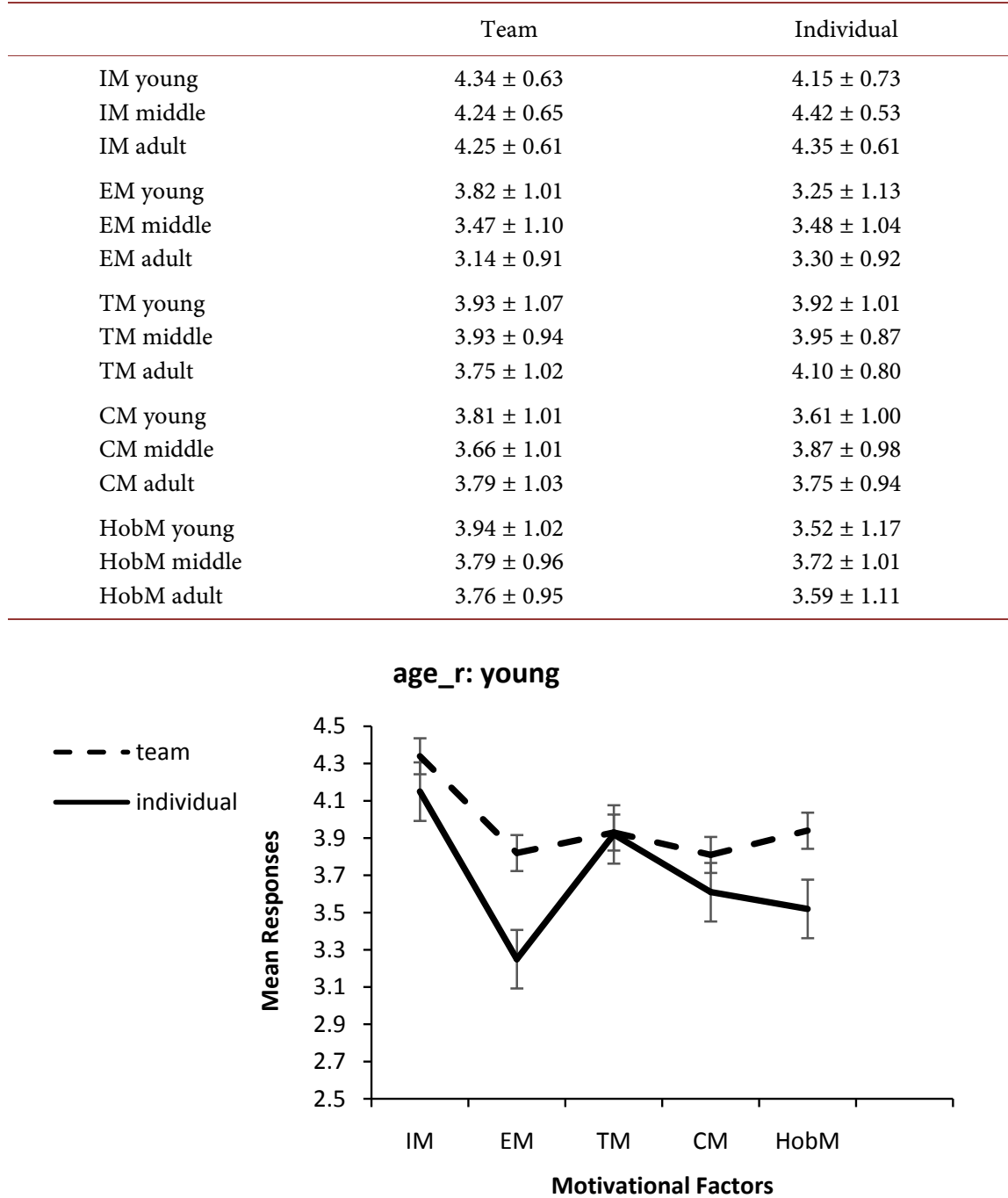

Figure 4. Differences between team and individual sports among the young group.

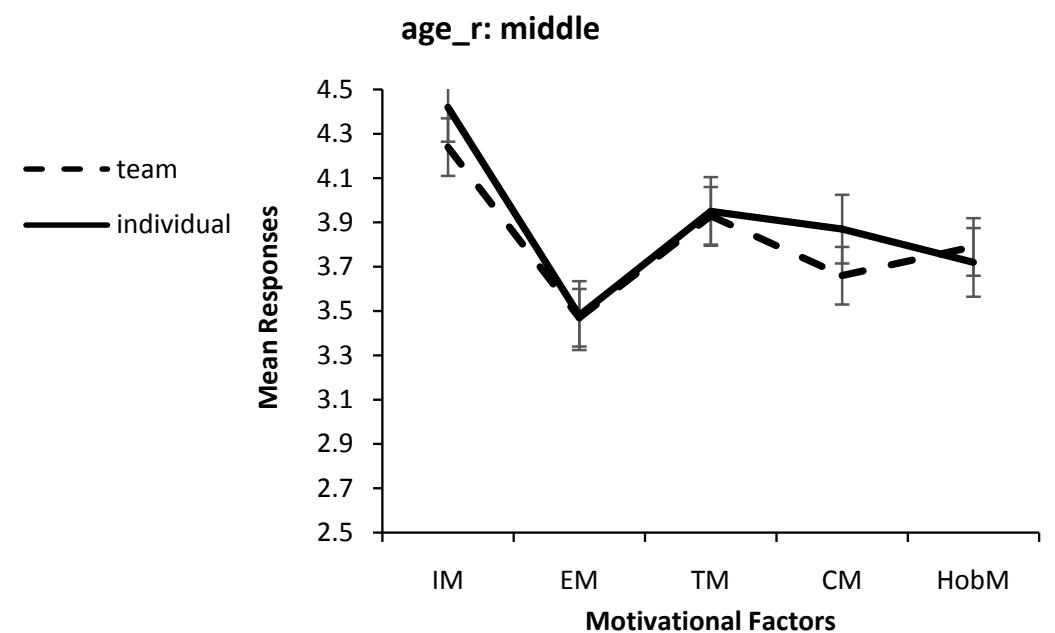

Figure 5. Differences between team and individual sports among the middle group. 
age_r: adult

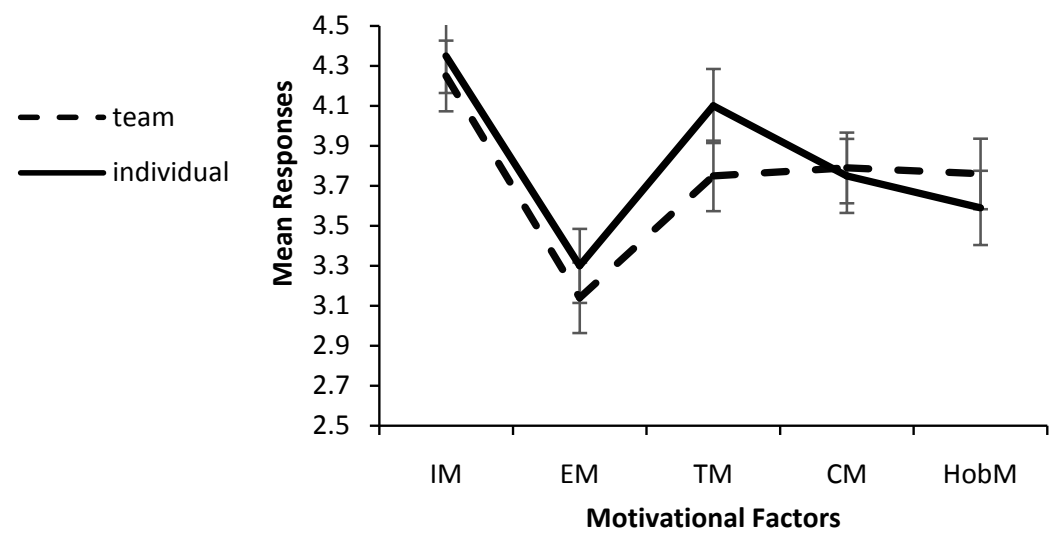

Figure 6. Differences between team and individual sports among the adult group.

young female athletes. These results correspond to existing data indicating that the dominant factor influencing the decision of youngsters to join competitive sport is intrinsic (Knight \& Holt, 2011; Ryan \& Deci, 2000a, b; Weinberg \& Gould, 2015). In addition, most of the studies focused on young males and the few studies which compared the genders indicated inconsistent results (e.g., Gonçalves et al., 2007; Moradi et al., 2020). Results of previous studies emphasized the importance of intrinsic motivation, focusing on "fun", while data of the current study emphasized reasons relating to the personal will of the young girls (e.g., "I want") and the need to win. The combination of these two factors paints a profile of young athletes with a strong will to participate in activities they choose with minimal external pressure. Coaches should be attentive to these two motivational factors. On the one hand, this profile is positive for achievement in sport since it indicates the athletes' strong personal will and decision. On the other hand, however, motivation based on the need to win may place the athlete under stress since it is impossible to expect to win on a regular basis. This trend/spirit can be explained based on cultural influences related to the countries under which the studies had been taken. Another important factor may relate to the $\mathrm{Z}$ generation, the first generation of truly digital natives. These young people have been exposed to the internet, to social networks, and to mobile systems (Gould et al., 2019). The pressure to win and to succeed is a core element in the modern cultural characteristic (Schinke et al., 2009). A common conclusion in the literature is that most of the motivation children have for participating in sport is intrinsic in nature and winning is not one of the most common reasons (Weinberg \& Gould, 2015). This conclusion is somewhat different than the findings in this study. Therefore, taking these elements into consideration, it is important that coaches integrate into the training process elements of games and physical activity focusing on personal fun and enjoyment, personal development, team building, and psychological skills to cope with the pressures of winning/losing. Similarly, to meet the needs of young female athletes, coaches should assist children to define winning not only as beating others but as setting 
and achieving personal goals and standards.

Noteworthy findings emerged from the comparison of motives to start individual sport vs team sport disciplines. Results indicate a similar effect of IM and TM in team and individual sports. However, in team sports, intrinsic, winning and health motivations are stronger than in individual sports. An interesting finding is that the motivation to be part of a team plays an equal role when comparing the motives to join individual and team sports. This means that when joining competitive sport, the effect of being part of a team is similar no matter what sport discipline is joined. This is in line with the SDT which claims that to create high intrinsic motivation, one should perceive a sense of belonging to other people (Ryan \& Deci, 2000a). Together with the fact that external motivation is not a major or dominant factor, the personality of young athletes can be portrayed as strong individuals who are relatively less susceptible to outside forces. There is no doubt that the role of the coach is critical and challenging. Coaches should teach young athletes how to connect to each other and cooperate, whether the sport is an individual or team effort.

Summarizing the motivational profile for starting sport activity, the dominant motivational factors are intrinsic, winning, and team. The coach, parents, and sport club staff should consider these findings and apply them in the training process, when necessary. Additional attention should be given to psychological aspects, such as knowledge, gender differences and skills which will promote motivation and eventually increase the number of young females who start sport competitive activity.

The other major goal of this study was to understand the motives of young female athletes to continue and adhere to competitive sport activity. The continue data will be discussed regarding all three age groups (i.e., young, middle, adults). The profile of the three age groups is similar with a dominant effect of IM and TM while some differences can be seen when comparing team and individual sports.

In the young group, athletes have already been engaged in competitive sport for at least one year and more. For this group, ages $9-11$ years, the data illustrate the effect of the training experience on young athletes, in team and individual sports. In general, both have similar motivational profiles, meaning that intrinsic motivation and team motivation are the dominant factors while external motivation has the lowest effect. In addition, when focusing on team sports, external motivation has a stronger effect compared to individual sports. In addition, the will to compete is not as dominant as was reported in relation to the motives to start competitive sporting activity. More specifically, the motivation to compete decreases especially for team sports. On the other hand, Zarrett and colleagues (2020) found ambivalent results. In some cases too much competition lowers the motivation to participate in sport and in other cases the desire for competition increases with age among young girls.

The influence of the coach and other players in team sports is greater compared to individual sports and to the motives to start. This gives the coach addi- 
tional means to influence players and to channel their motivation in the desired direction.

The middle group contains girls around the age of 12 - 13 years old and they have training experience of more than two years. For the middle group, the same motivational profile can be seen for individual and team sports. The most dominant factors are IM, TM, CM, and HobM, and EM is the lowest factor. These ages are usually risky as athletes may consider withdrawing from sport (Zach et al., 2012).

In the motivational profile IM can be seen as a dominant factor, while the other factors have less impact. Therefore, coaches should concentrate their attention on ways to improve team building, communication, and team cohesion, especially in team sports. In addition, focus should be on teaching young athletes' psychological skills, how to organize free time outside of practice, and how to recover from training and competition (e.g., relaxation).

The adult group contains girls around the age of $14-17$ years old with training experience of four years and more. The motivational profile of the adult group is like the middle group with a minor change. In individual sports, TM is stronger than in team sports, therefore, a coach should emphasize team building and team cohesion as factors to increase motivation to continue sport activity in team sport disciplines.

\section{Summary}

The present study delineated motivational profiles for young female athletes starting and continuing competitive sport activity in individual and team sport disciplines. Similarities and differences in motivational profiles were found across team and individual sport disciplines and three age groups. The results should be shared with the coaching staff and club administration to improve the motivation of young females to continue in competitive sport and to decrease the dropout rate. More specifically, coaches should focus on creating an environment that emphasizes enjoyment, competitiveness based on personal improvement, and connection to the team, including among individual sport disciplines. In addition, coaches should teach the young female athletes to evaluate their performance by their own standards of improvement rather than by competitive outcome (i.e., win/loss). All these can be achieved with the proper mental support to the athletes and to the coaching staff. Providing the mental support from a young age will assist the athletes when facing obstacles in their sport career. Future studies should focus on difficulties young female athletes face and on unique motivational profiles for specific sport disciplines. It is especially important to take into consideration the specific cultural characteristics and new communication means that may influence the motivational profile in sport among members of the Z-generation.

\section{Conflicts of Interest}

The authors declare no conflicts of interest regarding the publication of this paper. 


\section{References}

Azzarito, L., \& Solmon, M. A. (2009). An Investigation of Students' Embodied Discourses in Physical Education: A Gender Project. Journal of Teaching in Physical Education, 28, 173-191. https://doi.org/10.1123/jtpe.28.2.173

Bayyat, M. M. (2020). Identifying Motives for Sport Participation from the Perspective of Self-Determination Theory: Gender Differences. Dirasat: Educational Sciences, 47, 2020-2576.

Chantel, Y., Guay, F., Debreva-Martinova, T., \& Vallerand, R. J. (1996). Motivation and Elite Performance: An Exploratory Investigation with Bulgarian Athletes. International Journal of Sports Psychology, 27, 173-182.

Ciocan, D. M., \& Milon, A. (2017). Study Regarding the Motives of Children Participation in Sport Activities. LUMEN Proceedings, 1, 159-168.

https://doi.org/10.18662/lumproc.rsacvp2017.15

Crosnoe, R. (2001). The Social World of Male and Female Athletes in High School. In D. A. Kinney (Ed.), Sociological Studies of Children and Youth (Vol. 8, pp. 89-110). Bingley: Emerald Group Publishing Limited. https://doi.org/10.1016/S1537-4661(01)80006-4

Daley, A., \& O'Gara, A. (1998). Age, Gender and Motivation for Participation in Extra Curricular Physical Activities in Secondary School Adolescents. European Physical Education Review, 4, 47-53. https://doi.org/10.1177\%2F1356336X9800400105

Deci, E. L., \& Ryan, R. M. (1985). The General Causality Orientations Scale: SelfDetermination in Personality. Journal of Research in Personality, 19, 109-134.

https://doi.org/10.1016/0092-6566(85)90023-6

Fredricks, J. A., \& Eccles, J. S. (2006). Is Extracurricular Participation Associated with Beneficial Outcomes? Concurrent and Longitudinal Relations. Developmental Psychology, 42, 698-713. https://doi.apa.org/doi/10.1037/0012-1649.42.4.698

Gonçalves, C., Silva, M., \& Cruz, J. (2007). Gene Effect, Practical Context and Type of Sports Modality Regarding the Values in Youth Sports. Boletim of the Portuguese Society for Physical Education, 21, 71-86.

Gould, D., Feltz, D., \& Weiss, M. (1985). Motives for Participating in Competitive Youth Swimming. International Journal of Sport Psychology, 16, 126-140.

Gould, D., Nalepa, J., \& Mignano, J. (2019). Coach Generation Z Athletes. Journal of Applied Sport Psychology, 32, 104-120. https://doi.org/10.1080/10413200.2019.1581856

Harter, S. (1981). A New Self-Report Scale of Intrinsic versus Extrinsic Orientation in the Classroom: Motivational and Informational Components. Developmental Psychology, 17, 300-312. https://content.apa.org/doi/10.1037/0012-1649.17.3.300

Harter, S. (1992). The Relationship between Perceived Competence, Affect, and Motivational Orientation within the Classroom: Processes and Patterns of Change. In A. K. Boggiano, \& T. S. Pittman (Eds.), Achievement and Motivation: A Social-Developmental Perspective (pp. 77-115). Cambridge: Cambridge University Press.

Holt, N., \& Knight, C. (2014). Youth Sport, Participation Trends in. In R. Ecclund, \& G. Tenenbaum (Eds.), Encyclopedia of Sport and Exercise Psychology (pp. 786-788). Los-Angeles, CA: SAGE publication.

Knight, C. J., \& Holt, N. L. (2011). Sport Participation during Childhood and Adolescence. In N. L. Holt, \& M. Talbot (Eds.), Long Term Engagement in Sport and Physical Activity: Participation and Performance across the Lifespan (pp. 9-18). London: Routledge \& International Council of Sport Science and Physical Education. 
Meece, J., Glienke, B., \& Burg, S. (2006). Gender and Motivation. Journal of School Psychology, 44, 351-373. https://doi.org/10.1016/j.jsp.2006.04.004

Moradi, J., Bahrami, A., \& Dana, A. (2020). Motivation for Participation in Sports Based on Athletes in Team and Individual Sports. Physical Culture and Sport Studies and Research, 85, 14-21. https://doi.org/10.2478/pcssr-2020-0002

Nicholls, J. G. (1984). Achievement Motivation: Conceptions of Ability, Subjective Experience, Task Choice, and Performance. Psychological Review, 91, 328-346. https://content.apa.org/doi/10.1037/0033-295X.91.3.328

Prochaska, J. O., DiClemente, C. C., \& Norcross, J. C. (1992). In Search of How People Change: Applications to Addictive Behaviors. American Psychologist, 47, 1102-1114. https://doi.apa.org/doi/10.1037/0003-066X.47.9.1102

Roberts, G. C. (2001). Understanding the Dynamics of Motivation in Physical Activity: The Influence of Achievement Goals on Motivational Processes. In G. C. Roberts (Ed.), Advances in Motivation in Exercise and Sport (pp. 1-50). Champaign, IL: Human Kinetics.

Ryan, R. M., \& Deci, E. L. (2000a). Intrinsic and Extrinsic Motivations: Classic Definitions and New Directions. Contemporary Educational Psychology, 25, 54-67.

https://doi.org/10.1006/ceps.1999.1020

Ryan, R. M., \& Deci, E. L. (2000b). Self-Determination Theory and the Facilitation of Intrinsic Motivation, Social Development, and Well-Being. American Psychologist, 55, 68-78. https://doi.apa.org/doi/10.1037/0003-066X.55.1.68

Sabo, D. (2013). The Gender Gap in Youth Sports: Too Many Urban Girls Are Being Left Behind. Journal of Physical Education, Recreation \& Dance, 80, 35-40. https://doi.org/10.1080/07303084.2009.10598374

Schinke, R. J., Hanrahan, S. J., \& Catina, P. (2009). Introduction to Cultural Sport Psychology. In R. J. Schinke, \& S. J. Hanrahan (Eds.), Cultural Sport Psychology (pp. 3-12). Champaign, IL: Human Kinetics. http://doi.org/10.5040/9781492595366.ch-001

Soares, J., Antunnes, H., \& van den Tillaar, R. (2013). A Comparison between Boys and Girls about the Motives for the Participation in School Sport. Journal of Physical Education and Sport, 13, 303-307.

Spray, C. M., Wang, C. K. J., Biddle, S. J. H., \& Chatzisarantis, N. L. D. (2006). Understanding Motivation in Sport: An Experimental Test of Achievement Goal and Self Determination Theories. European Journal of Sport Science, 6, 43-51. https://doi.org/10.1080/17461390500422879

Vignadelli, L. Z., Ronque, E. R. V., Bueno, M. R. D. O., Dib, L. R. P., \& Serassuelo Jr, H. (2018). Motives for Sports Practice in Young Soccer and Volleyball Athletes. Revista Brasileira de Cineantropometria \& Desempenho Humano, 20, 585-597. https://doi.org/10.1590/1980-0037.2018v20n6p585

Wang, C. K. J., \& Liu, W. C. (2007). Promoting Enjoyment in Girls' Physical Education: The Impact of Goals, Beliefs, and Self-Determination. European Physical Education Review, 13, 145-164. https://doi.org/10.1177\%2F1356336X07076875

Weinberg, R. S., \& Gould, D. (2015). Foundations of Sport and Exercise Psychology (6th ed.). Champaign, IL: Human Kinetics.

Weinberg, R., Tenenbaum, G., McKenzie, A., Jackson, S., Anshel, M., Grove, R., \& Fogarty, G. (2000). Motivation for Youth Participation in Sport and Physical Activity: Relationships to Culture, Self-Reported Activity Levels, and Gender. International Journal of Sport Psychology, 31, 321-346.

Zach, S., Bar-Eli, M., Morris, T., \& Moore, M. (2012). Measuring Motivation for Physical 
Activity: An Exploratory Study of PALMS-The Physical Activity and Leisure Motivation Scale. Washington DC: American Psychological Association.

https://doi.apa.org/doi/10.1037/t41588-000

Zarrett, N., Veliz, P., \& Sabo, D. (2020). Keeping Girls in the Game: Factors That Influence Sport Participation. New York, NY: Women's Sports Foundation. 